\title{
Impact of the economic recession on emissions of greenhouse gases from agriculture in the Republic of Ireland
}

K Hanrahan, P R Gillespie, T Donnellan

Teagasc, RERC, Athenry, Galway, Ireland

Email: patrick.gillespie@teagasc.ie

Introduction Reductions in production, consumption, and transport also result in reduced emissions of greenhouse gases (GHG). However, recessions do not affect all sectors in the same way, and each sector's share of emissions will vary from country to country. Given the agricultural sector's unusually high contribution of 25.6 percent of total national GHG emissions (EPA, 2009), the aim of this analysis was to assess the impact of the economic recession on the projected path of emissions from the agricultural sector.

Material and methods The FAPRI-Ireland GHG model is a set of econometric, dynamic, multi-product, partialequilibrium commodity models as described in Hanrahan (2001). In its current version, the model covers markets for grains, other field crops, livestock and milk and dairy products. The FAPRI-Ireland GHG model projects the output levels for the various enterprises of the agricultural sector. When given these output figures and the relevant emission factors it is possible to apply the GHG accounting methodology set forth in the National Inventory Report (EPA, 2009) to arrive at projected GHG emission levels. We used a baseline - to - scenario comparison approach to tease out the effects of the recession on emissions through shocks to several key prices. These shocks are in fact the first revisions to pre-recession projections from the FAPRI EU Gold model, which the FAPRI-Ireland GHG model accepts as exogenous inputs. The key prices are international commodity prices which largely determine the price Irish producers will receive for their products on international markets, and thus will partially determine Irish output levels. The updates to these prices will imply new emission projections, and with all other variables held at their previous values the resultant distance between the reference and recession scenarios' projections is the impact of the recession on Irish agricultural emissions through 2020.

\section{Results}

Total $\mathrm{CO}_{2}$ equivalent emissions from the agriculture in Ireland in mega tonnes per annum

\begin{tabular}{|c|c|c|c|c|c|c|c|c|c|c|c|c|}
\hline & 2009 & 2010 & 2011 & 2012 & 2013 & 2014 & 2015 & 2016 & 2017 & 2018 & 2019 & 2020 \\
\hline Reference & 18.22 & 18.45 & 18.48 & 18.45 & 18.40 & 18.34 & 18.27 & 18.20 & 18.12 & 18.04 & 17.94 & 17.84 \\
\hline Recession & 18.21 & 18.36 & 18.34 & 18.29 & 18.21 & 18.11 & 18.01 & 17.91 & 17.81 & 17.70 & 17.59 & 17.47 \\
\hline $\begin{array}{l}\text { Percent } \\
\text { difference }\end{array}$ & $0.0 \%$ & $0.5 \%$ & $0.8 \%$ & $0.9 \%$ & $1.0 \%$ & $1.2 \%$ & $1.4 \%$ & $1.6 \%$ & $1.7 \%$ & $1.9 \%$ & $2.0 \%$ & $2.0 \%$ \\
\hline
\end{tabular}

Percent difference between Reference and Recession scenarios for selected livestock populations

\begin{tabular}{|c|c|c|c|c|c|c|c|c|c|c|c|c|}
\hline & 2009 & 2010 & 2011 & 2012 & 2013 & 2014 & 2015 & 2016 & 2017 & 2018 & 2019 & 2020 \\
\hline Cattle & $0.0 \%$ & $-0.1 \%$ & $-0.2 \%$ & $-0.1 \%$ & $-0.1 \%$ & $0.0 \%$ & $0.1 \%$ & $0.1 \%$ & $0.1 \%$ & $0.1 \%$ & $0.2 \%$ & $0.2 \%$ \\
\hline Sheep & $0.0 \%$ & $-1.8 \%$ & $-3.5 \%$ & $-4.2 \%$ & $-5.0 \%$ & $-5.6 \%$ & $-6.0 \%$ & $-6.4 \%$ & $-6.8 \%$ & $-7.3 \%$ & $-7.7 \%$ & $-8.1 \%$ \\
\hline Pigs & $-8.1 \%$ & $-12.8 \%$ & $-14.5 \%$ & $-17.8 \%$ & $-23.2 \%$ & $-28.7 \%$ & $-33.2 \%$ & $-37.1 \%$ & $-40.4 \%$ & $-43.3 \%$ & $-45.9 \%$ & $-48.4 \%$ \\
\hline
\end{tabular}

Conclusions The analysis shows that impacts on total emissions from the sector will persist but will be small in magnitude. The impact of the recession in 2009 is a 0.01 percent reduction in projected total GHG emissions relative to the reference scenario projections. By 2020, the impact of this recession will be to have reduced the projected level of emissions from the sector by only 2 percent. Whilst large percentage changes occur in the population figures for sheep and pigs throughout the projection period, no such effect is present in the cattle populations. With cattle being the most important livestock category in terms of emissions, the impact of the recession on the total emissions figure for the sector is severely dampened.

Acknowledgements The authors gratefully acknowledge funding from the ESRI.

\section{References}

Environmental Protection Agency (EPA). 2009. Ireland's Greenhouse Gas Emission in 2007: Greenhouse Gas Emissions 1990 - 2007 Reported To The United Nations Framework Convention On Climate Change. EPA, County Wexford, Ireland. Hanrahan, K. The EU GOLD Model 2.1: An Introductory Manual. 2001. Mimeo, Teagasc, Dublin. 